\author{
О.П. Ермакова \\ Калужский государственный университет \\ (Россия, Калуга) \\ olga_ermakova.kaluga@mail.ru
}

\title{
ПАРАДИГМАТИЧЕСКИ ОГРАНИЧЕННЫЕ МЕТОНИМИЧЕСКИЕ ЗНАЧЕНИЯ
}

В лингвистической литературе парадигматически ограниченные значения отмечались прежде всего в употреблении видов глагола. Так В. В. Виноградов писал о несовместимости некоторых переносных значений глагола казнить с формой совершенного вида. [Виноградов 1938: 144]. В толковых словарях такое ограничение лексических значений глаголов фиксируется, как правило. У существительных словари чаще других отмечают ограничения в формах числа. В статье рассматриваются парадигматически ограниченные метонимические значения, наблюдающиеся у разных лексических групп существительных, называющих состояния, стихийные явления и др. (тепло, холод, ветер, туман, снегопад и т. п.) в предложном падеже с предлогами $в$ и на, в винительном с предлогами на и $в$, в родительном падеже с предлогом с: 'там, где'; 'туда, где'; 'оттуда, где'; 'тогда, когда' - стоять на сквозняке; поставить на холод; прийти с мороза; купаться в иторм и т. п.

Наблюдения показывают, что отмеченные парадигматически ограниченные метонимические значения могут реализоваться и при метафорическом употреблении существительных. Это прежде всего свойственно художественной, особенно поэтической речи. Например: Уходит взвод в туман, в туман, в туман, а прошлое ясней, ясней, ясней (Б. Окуджава). Здесь туман 'неясное', 'неизвестное'.

Ключевые слова: парадигматика, метонимия, «прямая» метонимия, «обратная» метонимия, регулярная реализация, ограничения.

Известно, что некоторые значения слов могут быть парадигматически ограничены. В.В. Виноградов в свое время среди типов значений слов отмечал конструктивно обусловленные значения. В качестве примера он приводил так называемый творительный превращения: обернуться соколом, волком и m. n.

Ограничения здесь касаются и глагола: несовершенный вид - оборачиваться, очевидно, не принимает значения превращаться в кого - во что. О видовых ограничениях в семантике глагола также писал В.В. Виноградов. Им отмечено, 
в частности, распределение по видам значений глагола казнить: «Легко заметить, что значения сов. и несов. вида в формах глагола казнить сочетаются лишь с прямым, основным значением этого глагола: подвергать или подвергнуть смертной казни (курсив В.В. В). Другие же переносно-книжные значения слова казнить: 1) причинять кому-нибудь нравственное страдание, мучить, наказывать (казнить презрением) и 2) обличать, бичевать, клеймить (у столба сатиры разврат - и злобу я казнил. А. Пушкин) - функционируют лишь в формах несов. вида. Таким образом, дифференциация лексических форм слова казнить тесно связана с дифференциацией грамматической» [Виноградов 1938: 144].

Распределение лексических значений глаголов по видам рассматриваются также Ю.Д. Апресяном и М.Я. Гловинской. Так Ю.Д. Апресян пишет: Смотреть в «зрелищном» значении не связано никакими семантическими ограничениями. Между тем видеть в «зрелищном» значении реализуется лишь в прошедшем общефактическом [Апресян 1995: 62].

Наблюдения показывают, что среди глагольных форм «ущербными» нередко оказываются формы деепричастий: многие переносные и другие нецентральные лексические значения глагола не выражаются деепричастиями. Например: идти (об одежде), ивести (о человеке) и т. д.

Ср..*Платье, очень идя ей, несколько молодило женщину; *иветя в юности, она поблекла уже к 30 годам.

Неупотребительность некоторых значений в форме деепричастия, однако не значит, что переносные значения всегда «не терпят» деепричастий (или деепричастия переносных). Ср.: Кипя враждой нетерпеливой, ответа дома ждет поэт (А. Пушкин), но, возможно, некоторые значения не предназначены для сопроводительных действий.

В словарях наиболее последовательно парадигматические ограничения отмечаются у глаголов, прежде всего тогда, когда неупотребительность в некоторых формах имеет логическое объяснение. Ср.: толпиться - в 1 и 2 л., ед. ч. не употребляются; аналогично вечереть — он не всегда безличный, ср. день багряный вечерел (А. Пушкин). Ограничения форм лица и числа у безличных глаголов и личных в безличном употреблении также мотивируются их семантикой.

У существительных чаще других отмечаются ограничения в формах числа: холод (а) - 'холодная погода' только во множественном числе и т. п.

Таким образом, значения слов могут быть парадигматически ограничены: проявляться или, напротив, не проявляется лишь в некоторых формах слова.

Можно ли определить типы значений, регулярно проявляющихся как парадигматически ограниченные?

Наблюдения показывают, что среди разных видов метонимических значений есть такие, которые реализуются лишь в определенных падежно-предложных формах.

Я имею в виду употребление группы слов жара, тепло, холод, мороз, ветер, сквозняк, солние, свет, тень, тьма, туман и др. в предложном падеже с предлогом $н a$, в винительном падеже с предлогами на и в, в родительном падеже с предлогом 
c со значениями: 'там, где' и 'туда, где': стоять на солнце, на свету, на жаре, на ветру, на сквозняке; вынести на холод, поставить в тепло; а также в родительном падеже с предлогом с со значением 'оттуда, где' прийти с холода, с мороза и уйти с солнияа, прийти со света (в темноту).

Слово солнце реализуется в названных словоформах как источник света, тепла, жары; замечу, что название других светил - луна, месяц, звезды не употребляются со значениями 'там, где' и др. Можно сидеть (стоять) на солнце, но не на луне, месяце, звездах. Аналогично - уйти с солнцуа, но не слуны, смесяца, выйти на солнце (из тени, темноты), но не на луну, месяи, звезды, хотя свет исходит и от них.

Приведу некоторые текстовые примеры.

1. Значение 'там, где'.

Блестя на солнце снег лежит (А. Пушкин. Зимнее утро); И птица поет. $B$ коленкоровой мгле скрывается гром соловьиного лада (Э. Багрицкий. Стихи о соловье и поэте); Улыбнулся спокойно и жутко и сказал мне: "Не стой на ветру" (А. Ахматова. Сжала руки под тёмной вуалью); Он весь день сидит в духоте, пусть хоть немного побудет на воздухе (Устн. речь); Но ... на морозе голого долго не греет дым (И. Уткин. Повесть о рыжем Мотеле); Если б лечили правильно... если бы пил меньше... и зачем на сквозняке посидел... (А. Кабаков. Великие стройки апокалипсиса); Она лежала на сквозняке на полу в прихожей (М. Труб. Замочная скважина); Категорически не рекомендуется курить на морозе (А. Варшавская. Дым для дам); Да пойдем же, чего на холоде стоять (О. Павлов. Карагандинские девятины); После пребывания на солние или на холоде наша кожа теряет влагу, а значит, нуждается в тщательном уходе (И в зной, и в холод // «100\% здоровья», 2002. П.П.); Прыгали с парашютами, изнемогали на жаре... (В. Быков. Болото); Они целый день стоят на жаре, чтобы попасть к врачу (Д. Виноградов. Врачи прилетели); Они предчувствовали уже, что там, наверху и на свету не видеть им счастья [они в подвале O.E.] (А. Азольский. Лопушок).

2. 'Туда, где'.

Она звала меня куда-то в бесцельный зимний холод и в северный туман. (А. Блок. Она пришла с заката); Они так ласково меня из дома выгнали на вьюгу (А. Белый. Совесть); Поезд так быстро выходит на свет (С. Маршак. Туннель); И снова он едет один без дороги во тьму (Б. Окуджава. Ночной разговор); Он канул в туман и вернулся минут через десять (Д. Рубина. Белая голубка Кордовы); Выбегают, идут с галерей к воротам, под хоругви, от ворот - на мороз, на простор, подожженный зимой (Б. Пастернак. Детство).

3. 'Оттуда, где'.

Она пришла с мороза (А. Блок. Она пришла с мороза); Побегу кофейку сварю. Или лучше чаю покрепче, с метели-то (Т. Устинова. Где-то на краю света); С холода в тепле зубы ломит (Устн. речь), Каково ей - с африканской-то с жары в нашем климате (Устн. речь).

В словарях эти значения отмечаются непоследовательно. Так, значение 'там, где' - отмечено у слов холод, тепло, жар, но не отмечено у слов - сквозняк, мороз, дождь - хотя примеры с таким значением даются: Ср.: Холод - 4. Холодное, 
не нагретое место, помещение. Вынести нахолод; Тепло - Теплое, нагретое место, помещение. Кошка любит спать в тепле; Жар - 2. Место, где очень жарко. Сидеть на самом жару; Мороз - то же, что и холод в первом значении (т. е. «лишенное тепла, холодное состояние чего-либо») - толкование не соответствует примеру продрогнуть на морозе; При слове дождь не дается ни толкования — 'там, где', ни примеров типа Два часа стояла на дожде. Однако значение слова ветер сопровождается примером стоять на ветру и толкованием (в скобках) — “там, где дует ветер"; сквозняк сопровождается примером - не сиди на сквозняке, но толкование только - (сквозной ветер) [Толковый словарь русского языка 2008].

Этот же круг слов в винительном падеже с предлогом в нередко выражает временное значение 'тогда, когда'; (тогда, когда жара, холод, тьма и т. д.). Ср.: В такой холод (мороз, туман, зной, ветер, гололед), в такую жару (слякоть, тьму) лучше сидеть дома; в туман ехать опасно.

Некоторые текстовые примеры.

Он брал посох кизиловый, шёл в туман к Итилю-городу (Г. Садулаев. Таблетка); Однако, невиновность Писсаридзе тревожит Инку и толкает её во вьюгу и мороз плестись к тюрьме, прижимая к груди передачу (У. Нова. Инка); Технология такая, что от времени года никак не зависит. Можно делать и в жару, и в холод, и в снег, и в дождь (Т. Устинова. От первого до последнего слова); Иль подсолнечники в селах гаснут, - солнца, в пьль и в ливень (Б. Пастернак. Размолвка); Везет его в слякоть на телеге, на паре мужик (Ф. Достоевский); Узнаю в несчастной сей, в мороз и вьюгу, казачку юную мою, мою прекрасную подругу (Рылеев. Войнаровский); Ходит в зимушку студеную, ходит в летние жары (Н. Некрасов. Влас); Я дорожил и в тишь, и в бури то негой тающей лазури, то пеной у прибрежных скал (А. Фет. Л.Н. Толстому); Она гоняет, как собак, в ненастье, дождь и тьму пять тысяч Где, семь тысяч Как, сто тысяч Почему (Р. Киплинг. Есть у меня шестерка слуг. Пер. С. Маршака);

Употребляются слова этого типа (весь перечень с участием текстовых примеров здесь не приводится) с временным значением и в предложном падеже с предлогом в и на: На морозе петь трудно; Я в темноте почти ничего не вижу, езжу пока светло; Но злая пуля осетина его во мраке догнала (М. Лермонтов. Демон).

Кроме того, названия небесных светил луна, месяи, солнце, звезды с временным значением 'тогда, когда' употребляются в предложном падеже с предлогом при: Кто при звездах и при луне так поздно едет на коне? (А. Пушкин. Полтава); При луне на версте мороз огонечками (А. Фет. Снега. Ветер злой...). При месяце будут играть и летать (В. Жуковский. Лесной царь).

В толковых словарях этот тип значения, в отличие от 'туда, где'; 'там, где' не фиксируется при словах туман, тьма, жара, холод и др. подобных даже как особое употребление.

Метонимическое выражение времени в предложно-падежной форме требует отдельных замечаний.

Здесь наблюдается гораздо большее разнообразие лексики, чем в рассмотренных ранее обозначениях места. 
Можно отметить несколько групп слов, которые в сочетании с названными предлогами имеют метонимическое значение 'тогда, когда'.

1) Это название стихийных явлений: буря, гроза, вьюга, метель, ненастье, наводнение, половодье, разлив, ураган, иторм, снегопад, камнепад и др.

2) Общественные явления, события в мире людей: война, бомбежка, революция, разруха, правление, царствование и др.

3) Душевное эмоциональное состояние: горе, радость, тревога и др.

Их объединяет то, что это, как правило не мгновенное, однократное явление, а действие (состояние, событие) на фоне которого может происходить или предполагаться другое.

Некоторые примеры.

$B$ шторм купаться опасно (Устн. речь); Люба белоручка, Любушка пуглива. $B$ бурю за ворота выбежать ей в диво (Н. Некрасов. Буря); Три мудреца в одном тазу пустились по морю в грозу (Английская народная песня. Пер. С. Маршака); Я раз за дровами в лодке поехал - их много с реки, К нам в половодье весной нагоняет (Н. Некрасов. Дед Мазайи зайцы); В радости сыщут, а в горести забудут (Пословица); В войну все жили огородами; Он погиб не в револющию, а в правление Сталина (Устн. речь).

Разумеется, парадигматически ограниченные значения времени могут быть и у слов другой семантики, но, повторю, они не свойственны действиям мгновенным, однократным типа вылет, взмах, взлет, прыжок, скачок, плевки т. п.

Возникает вопрос: могут ли слова, называющие действие (процесс, событие, состояние), метонимически обозначать время вне предложнопадежных форм?

Судя по некоторым примерам из словарей, да, могут. Так, у слов жатва, косьба, сенокос, обед словари отмечают значение (время жатвы (сенокоса и др.). Но, как нам представляется, это свойственно названиям некоторых общественных явлений, традиционно (и по природе этих явлений) связанных с определенным временем года, дня, в частности, названий сельскохозяйственных работ или действий другого характера, например, пост, причастие или обед.

Но ни у названий стихийных природных, явлений, ни у других nom. act. метонимическое значение времени не наблюдается вне предложнопадежных форм.

В связи с тем, что значение места и времени “используют” одни и те же предлоги и, часто, слова одной и той же семантики, их различия не всегда очевидны. Ср.: Но злая пуля осетина его во мраке догнала (М. Лермонтов. Демон); Там, где был мрак (или тогда, когда наступил мрак). Глаза кошки светятся в темноте желтым или зеленым (А. Зайцев. Загадки эволюции): 'там, где темнота' или 'тогда, когда темно'.

Неразличение значений 'место' и 'время' преимущественно наблюдается в формах с предлогом в в винительном падеже - 'туда, где' и 'тогда, когда что-то' уходит в туман, в тьму — 'туда, где туман, и тьма' или 'тогда, когда туман и тьма'.

Возможно также и двусмысленное употребление некоторых слов в форме предложного падежа с предлогом на: на солнце, на свету. На солнще я сразу обгораю; На свету цвет платья меняется — 'там, где солнце (свет)' или 'тогда, когда солнце (свет)'. 
Значение 'оттуда, где', по-видимому, с временным не пересекается.

Все рассматриваемые метонимические значения наблюдаются и при метафорическом употреблении исходных слов. Это прежде всего свойственно художественной, особенно поэтической речи. Такое явление известно: и метафора может возникать на базе метонимии и метонимия на базе метафоры.

Например, слово муравейник может метафорически называть густо населенный дом, а в контексте - наш муравейник обсуждал телевизионные сплетни - называет жильцов дома, и это метонимия на базе метафоры.

В рассказе К. Чапека «История дирижера Калины» речь идет о двух людях, голоса которых дирижер определяет как кларнет и бас (метафора), но позже он пишет: «Я знал, что кларнет вернется домой и безвольно сделает то, что велел бас» (метонимия на базе метафоры).

Итак: в рассматриваемом мною явлении метафорическое значение существительных преобразуется в парадигматически ограниченную метонимию.

Наиболее часто во всех моделях — и 'там, где', и 'туда, где', и 'тогда, когда' с метафорически-метонимическими значениями у разных поэтов встречаются словоформы со словами - туман, мгла, мрак, тьма, темнота и др.

Ср.: Уходит взвод в туман, в туман, в туман, а прошлое ясней, ясней, ясней (Б. Окуджава).

Здесь туман 'неясное', 'неизвестное', но в это неясное и уходит взвод - (туда, где все неясно, туманно), а не туда, где туман как погодное явление.

Россия во мале (Г. Уэллс. Название книги); Но ты об этом не спеши, не обмануться бы во мраке, что звонче музыка атаки, что глуше музыка души (Б. Окуджава. Все глуше музыка души); И снова он едет один без дороги во тьму (Б. Окуджава. Ночной разговор); Денег не было, будущее тонуло во мраке (С. Довлатов. Чемодан); Но когда достигает предела. И душа отлетает во тьму - Поле пройдено, сделано дело. Вам решать: для чего и кому (Б. Окуджава. У поэта соперника нету);

Под шум и звон разнообразный

Под городскую суету

Я ухожу, душою праздный

В метель, во мрак и в пустоту. (А. Блок. Под шум и звон однообразный). Весь текст стихотворения метафорический.

На закате брежневского социализма в СССР потекли нефтедоллары (Р. Арифджанов. Москва азербайджанская); А на закате биографии ... роскошный шевиот отправился на хозяйство (Д. Рубина. Медная шкатулка).

Может возникнуть вопрос, обязательно ли считать эти значения метонимическими?

Слова жара, холод, мороз, тепло, сквозняк, ветер и под. называют состояние в природе, атмосферное явление, которое регулярно связано с местом и со временем. На основе этой регулярной связи и происходит перенос наименования, типичный для метонимии. Это перенос аналогичный актантной метонимии действие - место действия (спуск с горы - крутой спуск); действие - время действия (обед затянулся - встретимся в обед). Известно, что актантная метонимия имеет 
и обратную направленность: от актанта к действию: место - действие (ему грозит тюрьма); орудие действия - действие (его призвание - кисть и карандаш).

Но поскольку жара, мороз, туман и т. п. представляют собой некие аналоги действия (состояние), в частности могут сочетаться с фазисными глаголами жара началась, продолжается, прекратилась (аналогично - холод, ветер), то рассматриваемый вид метонимии, очевидно, близок к первому типу. Ср.: словарные толкования вторичных значений у таких слов как вход, выход - 'место, где входят', 'место, где выходят' и словоформ - на холоде, на жаре, на ветру 'место, где холод, жара, ветер' и т.д.

Итак, отмеченный нами тип метонимии, на наш взгляд, показывает существование парадигматически ограниченных значений как регулярное системное явление. Это не отдельные случаи проявления (или непроявления) некоторых периферийных значений слова, а регулярно проявляющиеся в определенных предложнопадежных формах у определенной лексической группы слов формализованные значения - 'там, где', 'туда, где', 'оттуда, где' и 'тогда, когда'. И, как нам представляется, лишний раз иллюстрирует не только связь, но и взаимопроникновение явлений лексики и грамматики.

\section{Литература}

Апресян Ю.Д. Лексическая семантика. Синонимические средства языка. М. : Наука, 1974. 368 с.

Апресян Ю.Д. Интегральное описание языка и системная лексикография. М. : Языки русской культуры, 1995. 767 с.

Виноградов B. В. Современный русский язык. Введение в грамматическое учение о слове. М.: Учпедгиз, 1938. 160 с.

Гак В.Г. Языковые преобразования. М. : Школа Языки русской культуры, 1998. $768 \mathrm{c}$.

Гинзбург Е. Л. Конструкции полисемии в русском языке. М. : Наука, 1954. 223 с.

Ермакова О.П. О семантической совместимости определений и предложно-падежных форм существительного // Вопросы синтаксиса русского языка. Калуга, $1971.257 \mathrm{c.}$

Ермакова О.П. Семантический эллипсис или семантический сдвиг? (О разговорном употреблении конструкций типа после селедки хочется пить, опоздал из-за детей) // Язык: поиски, факты, гипотезы. К 100-летию со дня рождения академика Н. Ю. Шведовой. М : Лексрус, 2016. 818 с.

Покровский М. М. Избранные работы по языкознанию. М. : Изд-во Акад. наук СССР, 1959. 382 с.

Толковый словарь русского языка. Отв. ред. Н.Ю. Шведова. М. : Азбуковник, 2008.

Толковый словарь русской разговорной речи (под ред. Л.П. Крысина), вып. 1-2, М. : Языки славянской культуры, 2014-2017. 


\author{
O.P. Ermakova \\ Kaluga state university \\ (Russia, Kaluga) \\ olga_ermakova.kaluga@mail.ru
}

\title{
PARADIGMATICALLY LIMITED METONYMIC MEANINGS
}

In linguistic literature, paradigmatically limited meanings were noticed, first of all, in the use of verbal aspects. Thus V.V. Vinogradov wrote about the incompatibility of some figurative senses of a verb with the perfective aspect. [Vinogradov 1938: 144]. In explanatory dictionaries such restrictions of lexical meanings of verbs are fixed, as a rule. With respect to nouns dictionaries note restrictions in number forms more often than other ones. In the given article paradigmatically limited metonymic meanings of various lexical groups of nouns denoting states, spontaneous phenomena, etc. (heat, cold, wind, fog, snowfall, etc.). in the instrumental case with the prepositions in and $o n$, in the accusative case with the prepositions on and in, in the genitive case with the preposition with: (there, where); (from where); (then, when) — to stand in the draught; to put out in the cold; to come from the cold; to bathe during a storm, etc. are considered. Observations show that paradigmatically limited metonimic meanings can emerge when nouns are used metaphorically as well. It is characteristic , mainly, of artistic, especially poetic speech, for example: The platoon goes to fog, to fog, to fog, and the past is clearer, clearer, clearer (B. Okudzhava). Here fog stands for something, which is not clear, unknown.

Keywords: paradigmatics, metonymy, "direct" metonymy, "return" metonymy, regular realization, restrictions.

\section{References}

Apresyan Yu.D. Leksicheskaya semantika. Sinonimicheskiye sredstva yazyka [Lexical semantics. Synonymic means of language]. Moscow, Nauka Publ. 1974. 368 c.

Apresyan Yu.D. Integral'noye opisaniye yazyka i sistemnaya leksikografiya [Integrated description of language and system lexicography]. Moscow, Yazyki russkoi kul'tury Publ. 1995. 767 p.

Vinogradov V.V. Sovremennyi russkii yazyk. Vvedenie v grammaticheskoe uchenie o slove [Modern Russian. Introduction to the grammatical doctrine about a word]. Moscow, Uchpedgiz Publ. 1938. 160 p.

V. G. Gak. Yazykovyye preobrazovaniya [Language transformations]. Moscow, Shkola Yazyki russkoy kul'tury Publ., 1998. 768 p.

Ginsburg E. L. Konstruktsii polisemii v russkom yazyke [Constructions of polysemy in Russian]. Moscow, Nauka Publ., 1954. 223 p.

Ermakova O.P. [About semantic compatibility of definitions and prepositional and case forms of a noun]. Voprosy sintaksisa russkogo yazyka [Problems of Russian syntax]. Kaluga, 1971. 
Ermakova O.P. [Semantic ellipsis or semantic shift? (About the colloquial usage of constructions thirsty after herring, late because of children)]. Language: search, facts, hypotheses. To the 100th anniversary of the academician N.Yu. Shvedova. Moscow, Lexrus Publ., 2016. 818 p.

Pokrovskii M. M. Izbrannyye raboty po yazykoznaniyu [Selected papers in linguistics]. Moscow, "Izd-vo Akad. nauk SSSR" Publ., 1959, 382 p.

Tolkovyy slovar' russkogo yazyka. Otv. red. N.Yu. Shvedova [Explanatory dictionary of Russian. Ed. by N.Yu. Shvedova]. Moscow, Azbukovnik Publ., 2008, 1175 p.

Tolkovyy slovar' russkoy razgovornoy rechi Pod red. L. P. Krysina [The Explanatory Dictionary of Russian Everyday Speech (ed. L.P. Krysin)], the issue 1-2, Moscow, Yazyki slavyanskoy kul'tury Publ., 2014-2017. 